\title{
Dento-skeletal characteristics of cleft patients with missing teeth
}

This article was published in the following Dove Press journal:

Clinical, Cosmetic and Investigational Dentistry

\author{
Waeil Batwa' \\ Hala A Almarhoon ${ }^{2}$ \\ Khalid A Almoammar ${ }^{2}$ \\ Nasser Alqahtani \\ Sahar F Albarakati \\ Thikriat Al-Jewair ${ }^{3}$ \\ 'Department of Orthodontics, \\ Faculty of Dentistry, King Abdulaziz \\ University, Jeddah, Saudi Arabia; \\ ${ }^{2}$ Department of Pediatric Dentistry \\ and Orthodontics, College of \\ Dentistry, King Saud University, \\ Riyadh, Saudi Arabia; ${ }^{3}$ Advanced \\ Education Program in Orthodontics \\ and Dentofacial Orthopedics, UMKC \\ School of Dentistry, Kansas City, MO, \\ USA
}

Correspondence: Waeil Batwa Department of Orthodontics, Faculty of Dentistry, building 14, Office 17, King Abdulaziz University, P.O. Box 80209, 21589 Jeddah, Saudi Arabia Tel +966 6952000 ext: 22I I 2 Email wbatwa@kau.edu.sa
Objective: The objective of this study was to compare the cephalometric skeletal and dental characteristics of unilateral complete cleft lip and palate (UCCLP) subjects with and without missing teeth.

Design: A retrospective records review was conducted for patients who are being treated at the cleft lip and palate (CLP) clinics in the College of Dentistry.

Methods : Ninety-six consecutive records of non-syndromic UCCLP subjects were recruited (33 subjects without missing teeth, 50 subjects with only one missing tooth, and 13 subjects with two or more missing teeth). Skeletal and dental characteristics were assessed using lateral cephalometric radiographs in UCCLP subjects with missing teeth and compared to the group with no missing teeth. A total of 25 linear and angular measurements were analyzed and compared between the sample groups.

Results: Of the dental variables tested, overjet was significantly different between the three groups. The UCCLP subjects with multiple missing teeth had the smallest overjet $(-3.89 \pm 2.75$ $\mathrm{mm} ; P=0.015)$ among the three groups. None of the skeletal characteristics reached statistical significance.

Conclusion: Missing teeth influence the dental but not skeletal characteristics of UCCLP. Overjet is significantly reduced in UCCLP subjects with multiple missing teeth. Future studies with larger sample sizes are warranted.

Keywords: missing teeth, cleft lip, cleft palate, hypodontia

\section{Introduction}

Cleft lip (CL), cleft lip and palate (CLP), and isolated cleft palate (CP) are all referred to as orofacial clefts; they are arguably the most common human craniofacial anomaly. ${ }^{1}$ Evidence-based research and anecdotal clinical observations have revealed adverse effects on craniofacial growth resulting from orofacial anomalies. ${ }^{2,3}$ These are caused by the intrinsic effects of the cleft anomaly and possibly as a result of treatment, such as scarring following the surgical closure of the cleft defects.

Orofacial clefts are associated with soft tissue and skeletal and/or dental defects. Such defects may manifest in the form of discontinuity of the lip/alveolar process, missing or malformed teeth, and skeletal deformity in three planes (anteroposterior, vertical, and transverse). ${ }^{4}$ These defects may consequently decrease the overall oral health-related quality of life in adults and children..$^{5-7}$ Lisson et $\mathrm{al}^{3}$ argued that surgical interventions influence the dental arch forms and alveolar development which restrict craniofacial growth, and this can be evident in the anteroposterior skeletal dimension. 
Although congenitally and/or developmentally missing teeth are seen in individuals with CLP, ${ }^{8-12}$ this type of dental anomaly varies according to ethnicity, cleft type, and gender. ${ }^{13-17}$ Cleft width, arch form, and shape of nasal septum can give information about lateral incisor agenesis. ${ }^{18}$ Furthermore, lateral incisor agenesis had been linked to deficient maxillary growth ${ }^{19,20}$ and dental arch discrepancy. ${ }^{21}$

In non-cleft patients, severe hypodontia, with more than six missing teeth has been linked to various craniofacial consequences, including a class III pattern, maxillary and mandibular angular prognathism, and maxillary restriction. ${ }^{22}$ A previous study have investigated tooth agenesis in cleft patients $^{23}$ and assessed anthropometric lip measurements. They found that lip measurements were predictive of the occurrence of dental anomalies (lateral agenesis). ${ }^{24}$

In a recent study, Wu et a ${ }^{25}$ evaluated a number of cephalometric characteristics present in Taiwanese individuals with unilateral CLP and found a general reduction in their skeletal vertical dimensions and a reduction in the overjet. Further studies are needed to explore the skeletal and dental characteristics of individuals with unilateral complete cleft lip and palate (UCCLP) in other ethnic groups, particularly Middle Eastern. Therefore, the aim of this study was to compare the cephalometric dentoskeletal characteristics of UCCLP individuals with and without missing teeth.

\section{Materials and methods Study design}

This retrospective study was based on the records of patients with orofacial clefts seen in the clinics of the CLP team. Ethical approval was obtained from the institutional Research Center, King Saud University, Riyadh, Saudi Arabia (PR 0026). Since this was a retrospective study in a teaching hospital where patients consented for their records to be used for research purposes, no further consent was obtained. All records were treated with confidentiality, and patients' name and personal data were kept anonymous. Skeletal and dental characteristics were assessed in UCCLP individuals with missing teeth and were compared to age- and gender-matched groups of individuals with UCCLP and no missing teeth. Linear and angular measurements obtained from lateral cephalometric radiographs were evaluated and compared between the sample groups.

\section{Sample characteristics}

Inclusion criteria were:

1. Individuals with UCCLP aged 7-14 years

2. Presence of complete records, including dental/medical files, panoramic radiographs, occlusal radiographs, and lateral cephalograms
Exclusion criteria were:

1. Patients who had undergone comprehensive orthodontic or orthopedic treatment

2. Those who had undergone any extraction treatment

3. Patients with poor-quality records

4. Patients who had undergone alveolar bone graft (ABG)

5. Patients who did not adhere to surgical treatment protocol

All patients with UCCLP were treated according to the standard protocol at the CLP team, College of Dentistry. Lip repair is undertaken between 3 and 6 months of age followed by palatal repair at around $9-12$ months. An ABG is performed around 9-11 years of age following the diagnosis of bone defect in the cleft site. The graft bone is harvested from the iliac crest. Presurgical orthodontic preparation is usually performed to facilitate the surgical access and primary closure during the alveolar bone grafting. Presurgical orthopedic treatment is not usually provided.

Records of patients who have been treated in the College of Dentistry (King Saud University, Riyadh, Saudi Arabia) from January 1991 to December 2014 were retrieved from the database of the CLP team and the orthodontic clinics. All records that met the inclusion criteria were investigated. Medical records were examined to obtain more data regarding the nature and extension of the cleft. The sample was divided into two main groups depending on the presence or absence of missing permanent teeth; individuals in the control sample (Group 1) had a full set of teeth (excluding third molars), whereas those in Group 2 were missing at least one tooth of any type (excluding third molars). Group 2 was further subdivided into two groups according to the number of teeth each individual was missing: Group 2A was composed of those who had only one missing tooth, and Group 2B included those who were missing two or more teeth.

Diagnosis of missing permanent teeth was made based on an interpretation of panoramic and occlusal radiographs taken between the ages of 7 and 14 years. The lateral cephalometric radiographs were taken prior to the ABG surgery and were traced and analyzed.

All selected cephalometric radiographs were taken with the patient's head in a natural position and with the teeth in centric occlusion. The radiographs were taken with a Planmeca Proline XC PAN/CEPH X-ray Unit (Planmeca Oy, Helsinki, Finland), set at 66-72 kV and $12 \mathrm{~mA}$, using $0.3-1$ seconds of exposure time, following the manufacturer's instructions. The magnification ratio at the midsagittal plane was $10.74 \%$ in the cephalometric film. The lateral cephalograms were scanned using the EPSON Perfection V700 Photo, a dual lens system (Epson Electronics Company, Suwa, Japan). The digitized 
radiographs were then traced and analyzed using Dolphin Imaging Software ${ }^{\circledR}$ (Version 11.7.05.66; Dolphin Imaging \& Management Solutions, Chatsworth, CA, USA).

One calibrated orthodontist traced and analyzed all radiographs after magnification adjustment.

\section{Cephalometric landmarks and measurements}

The selected landmarks are shown in Figure 1. A total of 25 linear and angular measurements were conducted. Seven angular, five linear, and one ratio were measured for skeletal features (Table 1). Six angular and five linear dental tissue measurements were measured as well (Table 2).

\section{Statistical analyses}

Data were analyzed using SPSS software (SPSS Version 22.0 for Windows; IBM Corporation, Armonk, NY, USA). The normality of the variables was assessed visually and through normality tests (Shapiro-Wilk test). Appropriate statistical tests were used depending on the normality of variables. Comparison of the three groups was performed using the parametric one-way ANOVA, followed by multiple

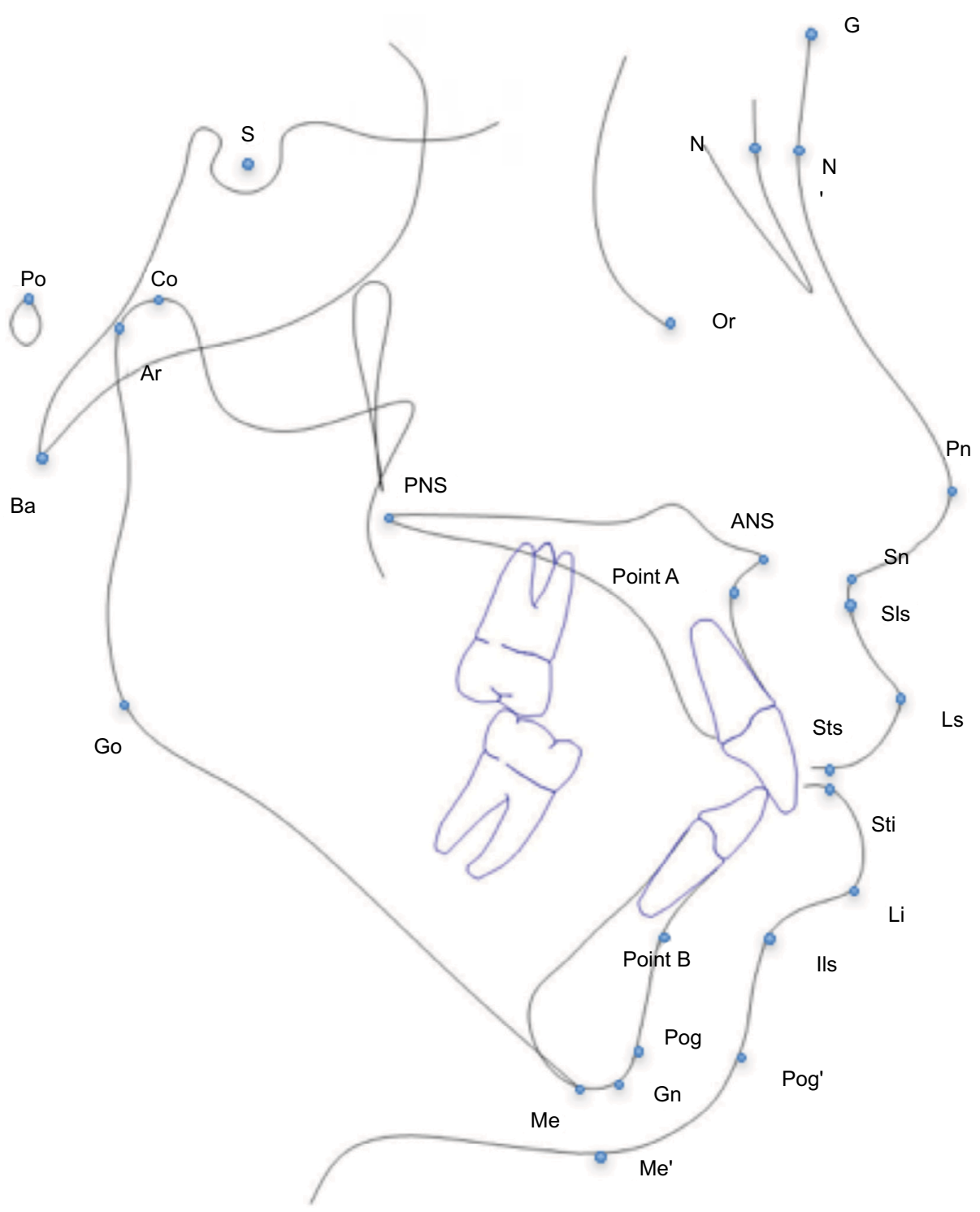

Figure I The skeletal, dental, and soft tissue landmarks used in the study.

Notes: S, sella turcica, center of the pituitary fossa of the sphenoid bone; $\mathrm{N}$, nasion, the junction of the frontonasal suture at the most posterior point on the curve at the bridge of the nose; Po, porion, the most superior point of the external auditory meatus; Or, orbital, the lowest point on average of the right and left lower borders of the bony orbit; Ba, basion, the most inferior posterior point of occipital bone at the anterior margin of the occipital foramen; Co, condyloid, the most posterior superior point of the condyle; ANS, anterior nasal spine, the tip of the anterior nasal spine; PNS, posterior nasal spine, the tip of posterior nasal spine; A, Point A, the most posterior (deepest) point on the curve of maxilla between the ANS and supradental (dental alveolus); UIA, upper incisor apex; UIE, upper incisor edge; LIE, lower incisor edge; LIA, lower incisor apex; B, Point B, the deepest point on the bony curvature along the anterior border of the symphysis; Pog, pogonion, the most anterior point on the contour of the mandible bony chin; Me, menton, the most inferior point on the symphysis of the mandible; Ar, articulare, intersection between the contour of the external cranial base and the dorsal contour of the condylar head; Go, gonion, the most convex point along the inferior border of the ramus; and Gn, gnathion, the point midway between the Me and Pog. 
Table I Skeletal measurements used in this study

\begin{tabular}{|c|c|c|c|}
\hline & Variable measured & Definition & Definition using landmarks \\
\hline \multicolumn{4}{|c|}{ Anteroposterior measurements } \\
\hline 1 & SNA $\left({ }^{\circ}\right)$ & $\begin{array}{l}\text { Prognathism of the maxillary alveolar bone to the } \\
\text { anterior cranial base }\end{array}$ & $S, N, A$ \\
\hline 2 & SNB $\left({ }^{\circ}\right)$ & $\begin{array}{l}\text { Prognathism of the mandibular alveolar bone to the } \\
\text { anterior cranial base }\end{array}$ & $\mathrm{S}, \mathrm{N}, \mathrm{B}$ \\
\hline 3 & ANB $\left({ }^{\circ}\right)$ & Sagittal jaw relationship angle & SNB minus SNA \\
\hline 4 & Wits appraisal (mm) & $\begin{array}{l}\text { Difference between the maxilla and the mandible in the } \\
\text { AP position }\end{array}$ & $\begin{array}{l}\text { Difference between point } A \text { and point B perpendicular } \\
\text { to the functional occlusal plane ( } U 6 \text { occlusal and } U 4 L 4 \\
\text { bisection) }\end{array}$ \\
\hline 5 & Convexity $\left({ }^{\circ}\right)$ & Convexity of the skeletal tissue & N-A-Pog \\
\hline 6 & Harvold analysis $(\mathrm{mm})$ & Difference in length between the two jaws & CoPog minus CoANS \\
\hline 7 & Maxilla position (mm) & Maxillary prognathism based on the McNamara analysis & $\begin{array}{l}\text { Distance from point } A \text { to a line perpendicular to Po Or } \\
\text { from } N\end{array}$ \\
\hline 8 & Mandible position (mm) & $\begin{array}{l}\text { Mandibular prognathism based on the McNamara } \\
\text { analysis }\end{array}$ & $\begin{array}{l}\text { Distance from Pog point to a line perpendicular to Po } \\
\text { Or from } N\end{array}$ \\
\hline \multicolumn{4}{|c|}{ Vertical measurements } \\
\hline 9 & $\operatorname{MPA}\left({ }^{\circ}\right)$ & Mandibular plane angle & $\begin{array}{l}\text { Me-Go line and S-N line } \\
\text { (MP-SN) }\end{array}$ \\
\hline 10 & $\operatorname{PPA}\left({ }^{\circ}\right)$ & Palatal plane inclination & ANS-PNS and Or-Po \\
\hline 11 & Y-Axis $\left({ }^{\circ}\right)$ & Growth pattern & N-S-Gn \\
\hline 12 & $\mathrm{ALFH}(\mathrm{mm})$ & Lower anterior facial height & ANS-Me distance \\
\hline 13 & PLFH (mm) & Lower posterior facial height & Ar-Go distance \\
\hline 14 & Vertical ratio & Facial height Index & LAFH/PLFH \\
\hline
\end{tabular}

Notes: S, sella turcica, center of the pituitary fossa of the sphenoid bone; $\mathrm{N}$, nasion, the junction of the frontonasal suture at the most posterior point on the curve at the bridge of the nose; Po, porion, the most superior point of the external auditory meatus; Or, orbital, the lowest point on average of the right and left lower borders of the bony orbit; Ba, basion, the most inferior posterior point of occipital bone at the anterior margin of the occipital foramen; Co, condyloid, the most posterior superior point of the condyle; ANS, anterior nasal spine, the tip of the anterior nasal spine; PNS, posterior nasal spine, the tip of posterior nasal spine; A, Point A, the most posterior (deepest) point on the curve of maxilla between the ANS and supradental (dental alveolus); UIA, upper incisor apex; UIE, upper incisor edge; LIE, lower incisor edge; LIA, lower incisor apex; B, Point B, the deepest point on the bony curvature along the anterior border of the symphysis; Pog, pogonion, the most anterior point on the contour of the mandible bony chin; Me, menton, the most inferior point on the symphysis of the mandible; Ar, articulare, intersection between the contour of the external cranial base and the dorsal contour of the condylar head; Go, gonion, the most convex point along the inferior border of the ramus; and Gn, gnathion, the point midway between the Me and Pog.

Table 2 Dental measurements used in this study

\begin{tabular}{|c|c|c|c|}
\hline & Variable measured & Definition & Definition using landmarks \\
\hline \multicolumn{4}{|c|}{ Anteroposterior measurements } \\
\hline I & $\mathrm{UI}-\mathrm{SN}\left({ }^{\circ}\right)$ & Upper incisors to anterior cranial base & SN to UIA - UIE \\
\hline 2 & $\mathrm{UI}-\mathrm{NA}\left({ }^{\circ}\right)$ & Upper incisor inclination relative to the jaw position & NA to UIA - UIE \\
\hline 3 & $\mathrm{UI}-\mathrm{NA}(\mathrm{mm})$ & Upper incisor protrusion relative to the jaw position & NA to UIE distance \\
\hline 4 & $\mathrm{UI}-\mathrm{PP}\left({ }^{\circ}\right)$ & Upper incisor inclination relative to the palatal plane & ANS-PNS to UIA - UIE \\
\hline 5 & $\mathrm{LI}-\mathrm{MP}\left({ }^{\circ}\right)$ & Lower incisor inclination to the mandibular plane & Me-Go to LIE - LIA \\
\hline 6 & $\mathrm{LI}-\mathrm{NB}\left({ }^{\circ}\right)$ & Lower incisor inclination relative to the lower jaw & NB to LI LIE - LIA \\
\hline 7 & $\mathrm{LI}-\mathrm{NB}(\mathrm{mm})$ & Lower incisor protrusion relative to the lower jaw & NB to LIE distance \\
\hline 8 & $\mathrm{LI}-\mathrm{APog}(\mathrm{mm})$ & Lower incisor protrusion relative to the chin & A Pog line to LIE distance \\
\hline 9 & Interincisal angle $\left({ }^{\circ}\right)$ & The angle formed between the upper and lower incisors & UIA-UIE to LIE-LIA angle \\
\hline 10 & Overjet $(\mathrm{mm})$ & The horizontal overlap between the upper and lower incisors (labial to labial) & UIE-LIE (horizontally) \\
\hline \multicolumn{4}{|c|}{ Vertical measurements } \\
\hline 11 & Overbite $(\mathrm{mm})$ & The vertical overlap between the upper and lower incisors & UIE-LIE (vertically) \\
\hline
\end{tabular}

Notes: S, sella turcica, center of the pituitary fossa of the sphenoid bone; $\mathrm{N}$, nasion, the junction of the frontonasal suture at the most posterior point on the curve at the bridge of the nose; ANS, anterior nasal spine, the tip of the anterior nasal spine; PNS, posterior nasal spine, the tip of posterior nasal spine; A, Point A, the most posterior (deepest) point on the curve of maxilla between the ANS and supradental (dental alveolus); UIA, upper incisor apex; UIE, upper incisor edge; LIE, lower incisor edge; LIA, lower incisor apex; B, Point B, the deepest point on the bony curvature along the anterior border of the symphysis; Pog, pogonion, the most anterior point on the contour of the mandible bony chin; Me, menton, the most inferior point on the symphysis of the mandible; Go, gonion, the most convex point along the inferior border of the ramus.

comparison tests using the Bonferroni method when a significant value was found. Since Group 1 was tested against Group 2A and 2B only, the $P$-value was adjusted to 0.025 . The Kruskal-Wallis test followed by the multiple comparison test was used for nonparametric variables.

\section{Intra-examiner reliability}

To evaluate intra-examiner reliability, 10 randomly selected lateral cephalometric radiographs were retraced and remeasured on two occasions with a 2-week interval, the two measurements for each radiograph were compared and 
Cohen Kappa was calculated. Dahlberg's formula was used to estimate the allocation error of the cephalometric points.

The intra-examiner reliability test (Cohen Kappa) indicated that all variables were highly reliable ( $r$ from 0.795 to $0.993)$, the $P$-value for the difference between the two sets of cephalometric measurements was not significant. Moreover, calculating the margin of errors using the Dahlberg's formula showed that the quantity of errors was between 0.2 and 1.2. This reflects highly reliable measures.

\section{Results}

The retrieved database included 499 individuals with orofacial cleft, of which 204 had a UCCLP. A total of 96 patients'

Table 3 Descriptive data of the sample

\begin{tabular}{llll}
\hline & \multicolumn{2}{l}{ Distribution of recruited sample } \\
\cline { 2 - 4 } & Group I & Group 2A & Group 2B \\
\hline Age, years & II.36 SD \pm I.7 & I0.6 SD \pm I.I & II.4 SD \pm I.5 \\
Gender (n) & Male (I7) & Male (20) & Male (7) \\
& Female (I6) & Female (30) & Female (6) \\
Total & 33 & 50 & I3 \\
\hline
\end{tabular}

Table 4 Distribution of missing teeth in the sample

\begin{tabular}{lll}
\hline Missing teeth & $\begin{array}{l}\text { Number of } \\
\text { subjects }\end{array}$ & $\%$ \\
\hline I Lateral incisor only & 44 & 69.84 \\
I Central incisor and I lateral incisor & 3 & 4.76 \\
I Lateral incisor and I premolar & 8 & 12.7 \\
2 Lateral incisors and I premolar & 2 & 3.17 \\
I Central incisor & 1 & 1.59 \\
I Premolar & 4 & 6.35 \\
2 Lateral incisors & 1 & 1.59 \\
Total & $\mathbf{6 3}$ & $\mathbf{1 0 0}$ \\
\hline
\end{tabular}

records met the preset inclusion criteria, among those 44 were male $(45.9 \%)$ and 52 were female $(54.1 \%)$, more details of age and gender distribution are found in Table 3.

The recorded age range of the recruited sample was 9-13 years with a mean of 10.94 years. All cephalometric radiographs were taken at an age of 9 years prior to orthodontic expansion and $\mathrm{ABG}$.

The main reported missing teeth in this study were the lateral incisors on the cleft side, followed by premolars and central incisors. The number of missing teeth ranged from zero to three teeth, with a mean of 1.25 per subject. A detailed distribution of the missing teeth is illustrated in Table 4.

No differences were found between the three groups in reference to the skeletal cephalometric characteristics (Table 5). In terms of dental features, overjet was significantly different among the three groups $(P=0.015)$. The rest of the dental measurements were not statistically significant (Table 6).

\section{Discussion}

This study included subjects with UCCLP who had not yet undergone ABG. Grafting serves as a bony support for teeth close to the cleft site, stabilizes the cleft maxillary segments, eliminates the notch in the alveolar ridge, supports the alar base, enables expansion of the maxillary suture, and improves facial symmetry. ${ }^{26}$ These effects can substantially influence the skeletal and dental cephalometric measurements. The same applies to extraction and orthodontic treatment. Our sample therefore excluded UCCLP subjects who had received ABG or orthodontic treatment with or without extraction.

When measurements in the anteroposterior dimension were assessed, there were no statistically significant differences in

Table 5 Comparison of skeletal measurements between Groups I, 2A and 2B using one-way ANOVA and Kruskal-Wallis test*

\begin{tabular}{|c|c|c|c|c|}
\hline Variable & $\begin{array}{l}\text { Group I } \\
\text { Mean } \pm \text { SD }\end{array}$ & $\begin{array}{l}\text { Group 2A } \\
\text { Mean } \pm \text { SD }\end{array}$ & $\begin{array}{l}\text { Group 2B } \\
\text { Mean } \pm \text { SD }\end{array}$ & P-value \\
\hline \multicolumn{5}{|c|}{ Skeletal anteroposterior measurements } \\
\hline SNA $\left({ }^{\circ}\right)$ & $76.66 \pm 4.89$ & $76.34 \pm 3.22$ & $76.07 \pm 4.34$ & 0.081 \\
\hline SNB $\left({ }^{\circ}\right)$ & $74.33 \pm 4.58$ & $74.18 \pm 4.86$ & $74.48 \pm 4.92$ & 0.259 \\
\hline ANB $\left({ }^{\circ}\right)$ & $2.33 \pm 3.85$ & $2.16 \pm 3.61$ & $1.59 \pm 3.22$ & $0.763^{*}$ \\
\hline Wits appraisal (mm) & $-3.82 \pm 5.06$ & $-4.43 \pm 5.00$ & $-4.10 \pm 10.32$ & $0.325^{*}$ \\
\hline Convexity $\left({ }^{\circ}\right)$ & $4.08 \pm 9.64$ & $2.91 \pm 7.91$ & $2.00 \pm 7.69$ & $0.716^{*}$ \\
\hline Harvold analysis (mm) & $23.53 \pm 6.37$ & $22.45 \pm 5.94$ & $22.75 \pm 5.93$ & 0.675 \\
\hline Maxilla position $(\mathrm{mm})$ & $-1.89 \pm 5.72$ & $-3.47 \pm 6.01$ & $-5.49 \pm 2.85$ & $0.094^{*}$ \\
\hline Mandible position (mm) & $-7.35 \pm 7.57$ & $-9.14 \pm 9.52$ & $-12.01 \pm 7.08$ & $0.161 *$ \\
\hline \multicolumn{5}{|c|}{ Skeletal vertical measurements } \\
\hline $\operatorname{MPA}\left({ }^{\circ}\right)$ & $43.14 \pm 8.09$ & $42.08 \pm 5.78$ & $44.55 \pm 5.98$ & 0.119 \\
\hline $\operatorname{PPA}\left({ }^{\circ}\right)$ & $-0.46 \pm 5.33$ & $-|.60 \pm 4.7|$ & $-1.89 \pm 3.77$ & 0.470 \\
\hline Y-Axis $\left({ }^{\circ}\right)$ & $72.02 \pm 5.39$ & $71.48 \pm 4.34$ & $73.74 \pm 4.34$ & 0.290 \\
\hline ALFH $(\mathrm{mm})$ & $63.22 \pm 5.72$ & $60.87 \pm 4.07$ & $62.67 \pm 4.48$ & 0.083 \\
\hline PLFH (mm) & $40.06 \pm 4.15$ & $39.18 \pm 3.73$ & $40.00 \pm 2.91$ & 0.623 \\
\hline Vertical ratio & $1.59 \pm 0.16$ & $1.57 \pm 0.14$ & $1.59 \pm 0.03$ & 0.821 \\
\hline
\end{tabular}

Note: *Indicates which P-value came from the Kruskal Wallis test. 
Table 6 Comparison of dental measurements between Groups I, 2A, and 2B using one-way ANOVA and Kruskal-Wallis test

\begin{tabular}{|c|c|c|c|c|}
\hline Variable & $\begin{array}{l}\text { Group I } \\
\text { Mean } \pm \text { SD }\end{array}$ & $\begin{array}{l}\text { Group 2A } \\
\text { Mean } \pm \text { SD }\end{array}$ & $\begin{array}{l}\text { Group 2B } \\
\text { Mean } \pm \text { SD }\end{array}$ & $P$-value \\
\hline \multicolumn{5}{|c|}{ Dental anteroposterior measurements } \\
\hline $\mathrm{UI}-\mathrm{SN}\left({ }^{\circ}\right)$ & $91.63 \pm 10.62$ & $91.62 \pm 12.35$ & $85.04 \pm 12.13$ & 0.198 \\
\hline $\mathrm{UI}-\mathrm{NA}\left({ }^{\circ}\right)$ & $14.96 \pm 9.65$ & $15.12 \pm 10.89$ & $11.48 \pm 11.80$ & $0.583 *$ \\
\hline UIE - NA (mm) & $0.76 \pm 3.69$ & $0.79 \pm 3.85$ & $-0.82 \pm 2.91$ & 0.290 \\
\hline UI - palatal plane $\left({ }^{\circ}\right)$ & $103.49 \pm 8.52$ & $104.11 \pm 13.01$ & $98.02 \pm 9.32$ & 0.253 \\
\hline IMPA $\left({ }^{\circ}\right)$ & $86.1 \pm 5.63$ & $85.16 \pm 7.12$ & $87.62 \pm 7.16$ & 0.618 \\
\hline $\mathrm{LI}-\mathrm{NB}\left({ }^{\circ}\right)$ & $23.56 \pm 5.70$ & $21.37 \pm 6.13$ & $24.13 \pm 8.23$ & 0.242 \\
\hline LIE - NB (mm) & $5.34 \pm 2.29$ & $4.34 \pm 2.20$ & $5.19 \pm 2.47$ & 0.089 \\
\hline LI - APog (mm) & $3.58 \pm 2.43$ & $2.48 \pm 2.61$ & $3.89 \pm 2.23$ & 0.027 \\
\hline Interincisal angle $\left({ }^{\circ}\right)$ & $139.15 \pm 8.97$ & $141.2 \pm 12.97$ & $142.78 \pm 9.44$ & 0.503 \\
\hline Overjet (mm) & $-1.44 \pm 3.81$ & $-0.69 \pm 3.55$ & $-3.89 \pm 2.75$ & $0.015^{* *}$ \\
\hline \multicolumn{5}{|c|}{ Dental vertical measurements } \\
\hline Overbite (mm) & $0.60 \pm 2.97$ & $0.86 \pm 3.07$ & $1.16 \pm 2.47$ & 0.901 \\
\hline
\end{tabular}

Notes: *Kruskal-Wallis test. **The significant finding after the statistical significant level was adjusted to 0.025 with Bonferroni. S, sella turcica, center of the pituitary fossa of the sphenoid bone; N, nasion, the junction of the frontonasal suture at the most posterior point on the curve at the bridge of the nose; ANS, anterior nasal spine, the tip of the anterior nasal spine; PNS, posterior nasal spine, the tip of posterior nasal spine; A, Point A, the most posterior (deepest) point on the curve of maxilla between the ANS and supradental (dental alveolus); UIA, upper incisor apex; UIE, upper incisor edge; LIE, lower incisor edge; LIA, lower incisor apex; B, Point B, the deepest point on the bony curvature along the anterior border of the symphysis; Pog, pogonion, the most anterior point on the contour of the mandible bony chin.

the ANB angle and facial convexity among the three groups. In fact, these groups exhibited a Class I skeletal pattern with an ANB angle ranging from $1.59^{\circ}$ to $2.33^{\circ}$. These findings were in agreement with Wu et al, ${ }^{25}$ who showed that these differences were not statistically significant despite the presence, or absence, of certain teeth. However, contrary to Wu et al, ${ }^{25}$ who found a significant reduction in the lower anterior face height with increasing missing teeth, this study did not find significant differences in lower face height between the groups.

Of the evaluated dental measurements, the overjet was statistically significantly different in the three groups $(P=0.015)$. This coincides with a previous study that found a significant difference in overjet among Taiwanese individuals with UCCLP and missing teeth in comparison with their counterparts without dental anomalies. ${ }^{25}$ The difference in overjet in our sample can be attributed to teeth tipping toward the anterior spaces, which occur as a result of missing teeth. The lower incisors in our sample were more protruded, relative to the chin (APog line) $(P=0.027)$, further contributing to the reduction in overjet as the number of missing teeth increased.

The reduced overjet in correlation to multiple missing teeth introduces a new challenge to orthodontists who are treating UCCLP, as cleft patients already present with Class III skeletal pattern. ${ }^{4}$ More reduction in overjet would require more complex treatment to normalize it. In some cases, UCCLP present with Class I skeletal pattern; in such cases, anchorage planning is very critical, especially in the anterior region, where it is required to keep the upper incisors proclined to facilitate overjet correction.
None of the skeletal findings in this study were statistically significant. These results disagree with the findings on non-cleft subjects suffering from a variety of missing teeth. Acharya et $\mathrm{al}^{22}$ reported that missing teeth in the anterior region had a significant effect in terms of the skeletal relationship, as the SNA decreased by $0.3^{\circ}$, SNB decreased by $0.1^{\circ}$, and ANB decreased by $0.2^{\circ}$ for every additional missing tooth. Although our findings were not significant, a pattern of ANB reduction can be noticed in the three groups, ANB of 2.33, 2.16, and 1.59 had been recorded for Groups 1, 2A, and 2B, respectively, yet this pattern could not be confirmed or proved.

Ideally, a priori sample size calculation should have been carried out. However, the nature of the studied sample (UCLP) and the extreme difficulty of allocating a good number of patients with good records limited the sample included in our study, especially in Group 2B. Moreover, only 96 (47\%) patients of the allocated 204 were recruited, which is due to the restricted inclusion criteria. The recruited sample who received surgical treatment with the same protocol from two surgical teams, although it would be more ideal to recruit the sample from one team work, which will reduce our sample further. Therefore, the results of this study must be considered with caution.

Missing teeth may influence cephalometric features for cleft patients, yet the cause and effect relationship cannot be explained by this cross-sectional study. Future studies should consider conducting longitudinal and multicenter investigations of craniofacial characteristics, along with the inclusion of a larger sample and a wider spectrum of cleft subjects. Also, the effects of cleft shape and size on growth 
were not verified or recorded in details within the medical notes. Thus, they were not assessed in this study. Nonetheless, all recruited patients were treated by the same team and following a standard protocol. Using $3 \mathrm{D}$ reconstruction software from CT scans as opposed to 2D films had been suggested to enable more accurate measurements to be taken specially with superimposed structures. ${ }^{27}$ However, this cannot be justified due to the excessive radiation.

Oral clefts exhibit a variety of clinical presentations; however, our investigation included only UCCLP anomalies. Nationally, researchers in the CLP field should undertake comprehensive projects to assess all types of orofacial clefts. These longitudinal and comprehensive research studies will enable health care providers to implement valid treatment protocols that are appropriate for the unique nature and complexity of the orofacial cleft population.

\section{Conclusion}

Missing teeth influence the dental characteristics of UCCLP. Overjet is significantly reduced in the group with multiple missing teeth. No statistically significant skeletal differences were found across the three groups.

\section{Disclosure}

The authors report no conflicts of interest in this work.

\section{References}

1. Coupland MA, Coupland AI. Seasonality, incidence, and sex distribution of cleft lip and palate births in Trent Region, 1973-1982. Cleft Palate J. 1988;25(1):33-37.

2. Lisson JA, Hanke I, Tränkmann J. Changes of vertical skeletal morphology in patients with complete unilateral and bilateral cleft lip and palate. Cleft Palate Craniofac J. 2005;42(5):490-494.

3. Lisson JA, Schilke R, Tränkmann J. Transverse changes after surgical closure of complete cleft lip, alveolus and palate. Clin Oral Investig. 1999;3(1):18-24.

4. Shetye PR. Update on treatment of patients with cleft-Timing of orthodontics and surgery. Semin Orthod. 2016;22(1):45-51.

5. Ward JA, Vig KW, Firestone AR, Mercado A, da Fonseca M, Johnston W. Oral health-related quality of life in children with orofacial clefts. Cleft Palate Craniofac J. 2013;50(2):174-181.

6. Queiroz Herkrath AP, Herkrath FJ, Rebelo MA, Vettore MV. Measurement of health-related and oral health-related quality of life among individuals with nonsyndromic orofacial clefts: a systematic review and meta-analysis. Cleft Palate Craniofac J. 2015;52(2):157-172.

7. Antonarakis GS, Patel RN, Tompson B. Oral health-related quality of life in non-syndromic cleft lip and/or palate patients: a systematic review. Community Dent Health. 2013;30(3):189-195.

8. Suzuki A, Takahama Y. Maxillary lateral incisor of subjects with cleft lip and/or palate: Part 1. Cleft Palate Craniofac J. 1992;29(4):376-379.
9. Jiroutová $\mathrm{O}$, Müllerová Z. The occurrence of hypodontia in patients with cleft lip and/or palate. Acta Chir Plast. 1994;36(2):53-56.

10. Tsai TP, Huang CS, Huang CC, See LC. Distribution patterns of primary and permanent dentition in children with unilateral complete cleft lip and palate. Cleft Palate Craniofac J. 1998;35(2):154-160.

11. Shapira $Y$, Lubit E, Kuftinec MM. Hypodontia in children with various types of clefts. Angle Orthod. 2000;70(1):16-21.

12. Al-Kharboush GH, Al-Balkhi KM, Al-Moammar K. The prevalence of specific dental anomalies in a group of Saudi cleft lip and palate patients. Saudi Dent J. 2015;27(2):75-80.

13. Aizenbud D, Camasuvi S, Peled M, Brin I. Congenitally missing teeth in the Israeli cleft population. Cleft Palate Craniofac $J$. 2005;42(3):314-317.

14. Pegelow M, Alqadi N, Karsten AL. The prevalence of various dental characteristics in the primary and mixed dentition in patients born with non-syndromic unilateral cleft lip with or without cleft palate. Eur $J$ Orthod. 2012;34(5):561-570.

15. Paranaiba LM, Coletta RD, Swerts MS, Quintino RP, de Barros LM, Martelli-Júnior H. Prevalence of Dental Anomalies in Patients With Nonsyndromic Cleft Lip and/or Palate in a Brazilian Population. Cleft Palate Craniofac J. 2013;50(4):400-405.

16. Mikulewicz M, Ogiński T, Gedrange T, Berniczei-Royko A, Prussak E. Prevalence of second premolar hypodontia in the Polish cleft lip and palate population. Med Sci Monit. 2014;20:355-360.

17. Al Jamal GA, Hazza'a AM, Rawashdeh MA. Prevalence of dental anomalies in a population of cleft lip and palate patients. Cleft Palate Craniofac J. 2010;47(4):413-420.

18. Doucet JC, Delestan C, Montoya P, et al. New neonatal classification of unilateral cleft lip and palate part 2: to predict permanent lateral incisor agenesis and maxillary growth. Cleft Palate Craniofac $J$. 2014;51(5):533-539.

19. Antonarakis GS, Fisher DM. Permanent Tooth Agenesis and Maxillary Hypoplasia in Patients with Unilateral Cleft Lip and Palate. Plast Reconstr Surg. 2015;136(5):648e-656e

20. Lai LH, Hui BK, Nguyen PD, et al. Lateral incisor agenesis predicts maxillary hypoplasia and Le Fort I advancement surgery in cleft patients. Plast Reconstr Surg. 2015;135(1):142e-148e.

21. Hardwicke J, Chhabra P, Richard B. Absent maxillary lateral incisor as evidence of poor midfacial growth in unilateral cleft lip and palate. Oral Surg Oral Med Oral Pathol Oral Radiol. 2015;119(4): 392-395.

22. Acharya PN, Jones SP, Moles D, Gill D, Hunt NP. A cephalometric study to investigate the skeletal relationships in patients with increasing severity of hypodontia. Angle Orthod. 2010;80(4):511-518.

23. Lai MC, King NM, Wong HM. Abnormalities of maxillary anterior teeth in Chinese children with cleft lip and palate. Cleft Palate Craniofac J. 2009;46(1):58-64.

24. Antonarakis GS, Fisher DM. Presurgical Unilateral Cleft Lip Anthropometrics and the Presence of Dental Anomalies. Cleft Palate Craniofac J. 2015;52(4):395-404.

25. Wu TT, Ko EW, Chen PK, Huang CS. Craniofacial characteristics in unilateral complete cleft lip and palate patients with congenitally missing teeth. Am J Orthod Dentofacial Orthop. 2013;144(3):381-390.

26. Kuijpers-Jagtman AM, Long RE. The influence of surgery and orthopedic treatment on maxillofacial growth and maxillary arch development in patients treated for orofacial clefts. The Cleft Palate-Craniofacial Journal. 2000;37(6):1-12.

27. Tulunoglu O, Esenlik E, Gulsen A, Tulunoglu I. A comparison of threedimensional and two-dimensional cephalometric evaluations of children with cleft lip and palate. Eur J Dent. 2011;5(4):451-458. 


\section{Publish your work in this journal}

Clinical, Cosmetic and Investigational Dentistry is an international, peer-reviewed, open access, online journal focusing on the latest clinical and experimental research in dentistry with specific emphasis on cosmetic interventions. Innovative developments in dental materials, techniques and devices that improve outcomes and patient satisfac- tion and preference will be highlighted. The manuscript management system is completely online and includes a very quick and fair peerreview system, which is all easy to use. Visit http://www.dovepress. com/testimonials.php to read real quotes from published authors.

Submit your manuscript here: https://www.dovepress.com/clinical-cosmetic-and-investigational-dentistry-journal 